OPEN ACCESS

Edited by:

Francis Verpoort

Wuhan University of

Technology, China

Reviewed by:

Zhihua Xu

Jianghan University, China

Yan Liu,

Shanghai Jiao Tong University, China

Vincenzo Palma,

University of Salerno, Italy

Eugenio Meloni,

University of Salerno, Italy, in collaboration with reviewer VP

*Correspondence: Xin Gao

gaoxin@tju.edu.cn

Specialty section: This article was submitted to Catalysis and Photocatalysis,

a section of the journal

Frontiers in Chemistry

Received: 10 December 2019 Accepted: 06 April 2020 Published: 05 May 2020

Citation:

Li H, Zhang C, Pang C, Li X and Gao X (2020) The Advances in the Special Microwave Effects of the Heterogeneous Catalytic Reactions.

Front. Chem. 8:355.

doi: 10.3389/fchem.2020.00355

\section{The Advances in the Special Microwave Effects of the Heterogeneous Catalytic Reactions}

\author{
Hong Li ${ }^{1,2}$, Chunyu Zhang ${ }^{1}$, Chuanrui Pang ${ }^{1}$, Xingang $\mathrm{Li}^{1}$ and Xin Gao ${ }^{1 *}$ \\ ${ }^{1}$ School of Chemical Engineering and Technology, National Engineering Research Center of Distillation Technology, \\ Collaborative Innovation Center of Chemical Science and Engineering (Tianjin), Tianjin University, Tianjin, China, ${ }^{2}$ TJU Binhai \\ Industrial Research Institute Limited Company, Tianjin, China
}

In the present, microwave field has been widely used in chemical processes as an important means of intensification. The heterogeneous catalysts coupling with microwave has been shown to have many advantages, such as high catalytic performance and stability. Our objective is to focus an up-to-date overview concerning the advances in the special microwave effects of the heterogeneous catalytic reactions including special thermal effect, microwave plasma, enhanced active groups, and the flexibility of structure. This review systematically states the action mechanism and some practical application of microwave-induced catalytic process. Finally, the potential research directions in the field of microwave-induced catalysis are prospected.

Keywords: microwave, catalysis, special thermal effect, plasma, process intensification

\section{INTRODUCTION}

As a common way of process intensification (PI) technology, microwave field, which is constituted of alternating magnetic and electric fields, has the advantages of volumetric heating, energy saving and higher selectivity (Chandrasekaran et al., 2012; Binner et al., 2013; Roy et al., 2017), and has been more and more popular in various chemical processes. In the courses of relative volatility, reactive distillation, drying and membrane separation (Li et al., 2017, 2019c; Gao et al., 2018), the addition of microwave irradiation can greatly facilitate the process. At the meantime, a great number of scholars have introduced microwave into the field of heterogeneous catalytic reactions (Gao et al., 2019; Li et al., 2019a,b; Zhang et al., 2019). Earlier microwave-assisted catalytic reactions can be traced back to 1992. Adámek and Hájek (1992) applied microwave to the reactions of tetrachloromethane and ethyl trichloroacetate with styrene in the presence of metal complexes. The reaction rate of microwave irradiation can be increased for several folds compared to that of conventional heating. As a result, the synergistic use of microwaves and catalysts emerged in multiple forms and reactions. In order to expand the practical application of microwave, it is necessary to study the mechanism of microwave action. As good microwave absorbers, solid catalysts can be heated rapidly due to high dielectric properties such as carbon particles. In terms of molecular level, polar molecular can rotate rapidly with the alternating electromagnetic field and produce ions migration (Sajjadi et al., 2014; Hirota et al., 2017). In the process of microwave irradiation, the molecular thermal motion increases and the heating efficiency is determined by molecular dipole (Oh et al., 2017). In addition, the structure of solid catalysts supported by polar functional groups or enzymes can change under microwave field for the special function.

In this paper, we state various effects of microwave on catalysts and classify according to the mechanism. Microwave can accelerate the reaction by the special thermal effect, plasma, special 
active effect and changing the structure of enzyme. This review analyzes and summarizes various influences through practical reactions. After introducing the microwave-induced process, we put forward some unsolved problems for the mechanism and the prospect of its application. The review can give the following scholars better guidance and understanding of microwaveinduced heterogeneous catalytic technology.

\section{SPECIAL THERMAL EFFECT OF MICROWAVE ON SOLID CATALYSTS}

Thermal effect of microwave is the phenomenon that microwave energy is absorbed by dielectric materials and converted into heat energy, which is shown as the total loss of microwave energy in materials. The special thermal effect, as shown in Scheme 1, is also known as hot spot and has been discovered by many scholars (Jiang et al., 2018; Vakili et al., 2018).

For liquid phase reactions, the temperature of solid catalysts is higher than that of solvent owing to special thermal effect. Bogdal et al. (2002) found heterogeneous thermal effect by using Magtrieve which is an oxidant on the basis of tetravalent chromium dioxide $\left(\mathrm{CrO}_{2}\right)$ that can absorb microwave and convert energy into heat. It was found that the temperature the center of solid catalyst is higher than other parts and solvent in the microwave field. The oxidation of alcohols to carbonyl with Magtrieve under microwave irradiation was following researched. The higher temperature of the solid support can lead to higher conversion of reactants and higher reaction rates. The special local thermal effect of microwave and Magtrieve will provide a good reaction environment to promote oxidation reaction. Owing to the high temperature of the solid catalyst in the microwave field, they got higher yield and save the reaction time in comparison with conventional heating. Mishra et al.
(2019) degraded Brilliant Green (BG) by means of microwaveassisted catalytic spinel zinc ferrite (SZFO) sheets. SZFO firstly adsorbed BG and subsequently is exposed to MW irradiation under the output power of $360 \mathrm{~W}$ at $2.45 \mathrm{GHz}$. The result showed that $99 \%$ of the total removal efficiency can be obtained within $5 \mathrm{~min}$ and got inorganic ions. SZFO can efficient absorb MW energy, which form a local high temperature area at the catalyst surface. The BG will be adsorbed on the catalyst surface and the high temperature can break the bonds of BG, e.g., C-H or C-C. At the same time, microwave irradiation can activate SZFO to be a semiconductor and generate electrons and holes which can oxidize BG to $\mathrm{CO}_{2}$ and $\mathrm{H}_{2} \mathrm{O}$. Haneishi et al. (2019) researched the catalytic dehydrogenation reaction of 2-propanol into acetone using microwave $(2.45 \mathrm{GHz})$ and conventional heating, respectively. It was found that the yield of acetone by MW irradiation were 19 and 12 times higher than that under conventional heating in 2.5 and $20 \mathrm{~s}$. The reaction rate of microwave heating is also more than 10 times relative to conventional heating. The magnetite solid catalyst can absorb MW energy and generate a local high-temperature regions at the contact points which facilitates the reaction.

Transesterification is a kind of important chemical reaction which generally uses acid as catalyst. The liquid acid is poorly in catalytic performance and corrodes the equipment. A new microwave-assisted transesterification (MAT) technology with solid acid catalysts is used for transesterification. Nayak et al. (2019) reviewed the biodiesel synthesis by using microwave-assisted transesterification technology with various homogeneous and heterogeneous catalysts. Heterogeneous catalysts are easier to separate from the product and reuse compared to homogeneous catalysts. There are many types of heterogeneous catalysts, including metal oxides, mixed oxide, exchange membrane, carbon/ clay supported catalyst and enzymes mentioned below rather than homogeneous acid or

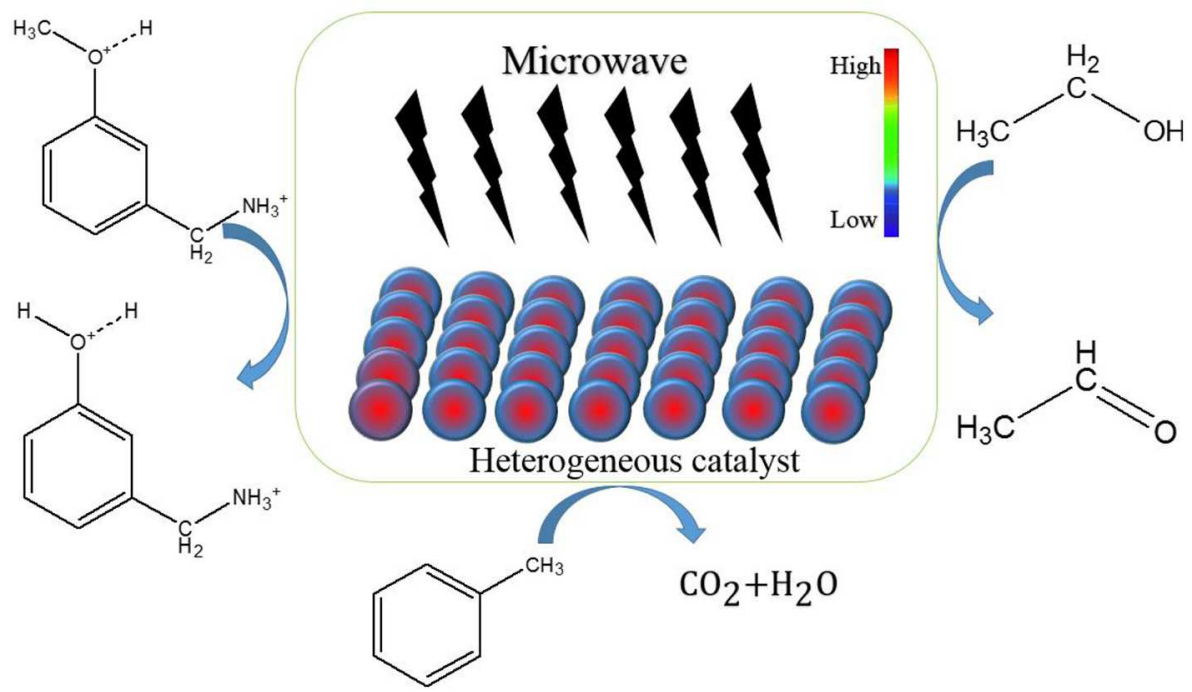

SCHEME 1 | The schematic diagram of the special thermal effect of microwave on solid catalysts. 
base. The multiple selectivity of heterogeneous catalysts allows us to find the best catalyst in the appropriate reaction. $\mathrm{H}_{2} \mathrm{SO}_{4} / \mathrm{C}$ solid acid catalyst is selected for transesterification of biodiesel under microwave field (2.45 GHz, $200 \mathrm{~W}$ ) (Yuan et al., 2009). Both activated carbon and sulfuric acid are of high dielectric properties and absorb microwave. $\mathrm{H}_{2} \mathrm{SO}_{4} / \mathrm{C}$ solid acid catalyst can also produce "microwave hot spots" under microwave irradiation, which means the temperature of catalyst is higher than that of liquid. In the case of heterogeneous acid catalysts, the high reaction temperature from "microwave hot spots" offsets the reduction of activity due to mass transfer resistance. In addition, the heterogeneous solid catalysts are able to react on the internal and external surfaces simultaneously. The high temperature is to the benefit of the endothermal reaction, so the yield of transesterification of biodiesel using $\mathrm{H}_{2} \mathrm{SO}_{4} / \mathrm{C}$ solid acid catalyst under microwave irradiation is improved. The results showed that microwave-assisted catalytic transesterification can reach a maximum yield of $94 \%$ compared with conventional heating. Prakash et al. (2015) compared the performance of glycerol and char (carbon particles) in the process of microwave pyrolysis. Its rated output is $800 \mathrm{~W}$ with a microwave frequency of 2,450 MHz. The results of experiments were that the yield obtained by using char as the microwave absorber is more than glycerol. The reason for this phenomenon is that char particles have a higher dielectric property than glycerol so that it can absorb more microwave energy. Therefore, char particles can act as energy sources to sustain the pyrolysis process and advance the reactions further.

The occurrence of solid phase reactions usually requires high temperature (Ren et al., 2015). Microwave irradiation can achieve high temperature conditions in a short time without introducing impurities. Pure $\mathrm{ZnO}$ and $\mathrm{ZnO}$ concentrate can't absorb microwave while carbon, as the reducing agent, can absorb microwave energy (Saidi and Azari, 2005). Microwave heating was carried out at a frequency of $2.45 \mathrm{GHz}$ in two power levels, 900 and 1,000 W. The microwave energy absorbed by carbon can convert to heat which provides a high temperature environment for $\mathrm{ZnO}$ or $\mathrm{ZnO}$ concentrate. The electric loss factor of $\mathrm{ZnO}$ increases with the enhancement of surrounding temperature. The reduction reaction takes place in the critical temperature. The rate is increased and the product is reduced better under microwave irradiation.

The catalytic oxidation of toluene vapor by nano-size $\mathrm{Co}_{3} \mathrm{O}_{4}$ is conducted in the microwave field (Yi et al., 2018). The results showed that microwave irradiation can promote the removal rate of toluene in the low temperature. The interpretation for this phenomenon is the hypothesis of "hot spots." Microwave irradiates heterogeneous nano- $\mathrm{Co}_{3} \mathrm{O}_{4}$ and increase the temperature of bulk surroundings. But the temperature of a certain micro-region is higher than the macroscopic temperature owing to the quick absorption of microwave energy. The solid catalyst provides a position for the conversion of active oxygen and oxygen vacancies. The special thermal effect makes the catalytic oxidation reaction continuous and efficient. Julian et al. (2019b) developed Mo-ZSM5 catalyst coated on silicon carbide monolith for methane under non-oxidative conditions. The resonant frequency of microwave is around $2.45 \mathrm{GHz}$. It can be observed that the temperature of gas is lower than that of catalyst
TABLE 1 | Summary of special thermal effect of microwave on solid catalysts.

\begin{tabular}{|c|c|c|c|c|c|c|}
\hline Feed stock & Catalyst & Time/min & Temp $/{ }^{\circ} \mathbf{C}$ & MW/W & MW/MHz & Yield \\
\hline 1-octanol & Magtrieve & 25 & 360 & - & - & 99 \\
\hline Brilliant Green & $\begin{array}{l}\text { spinel zinc } \\
\text { ferrite }\end{array}$ & 5 & $>1,000$ & 360 & 2,450 & 99 \\
\hline 2-propanol & $\begin{array}{l}\text { magnetite } \\
\text { catalyst }\end{array}$ & 20 & 250 & - & 2,450 & 25 \\
\hline $\begin{array}{l}\text { Fatty acid } \\
\text { methyl ester }\end{array}$ & $\mathrm{H}_{2} \mathrm{SO}_{4} / \mathrm{C}$ & 60 & 65 & 200 & 2,450 & 94 \\
\hline Bagasse & char & 30 & 110 & 800 & 2,450 & 55 \\
\hline $\begin{array}{l}\mathrm{ZnO} \text { or } \mathrm{ZnO} \\
\text { concentrate }\end{array}$ & carbon & 9 & $>1,000$ & 1,000 & 2,450 & $>80$ \\
\hline Toluene & $\begin{array}{l}\mathrm{CO}_{3} \mathrm{O}_{4} \\
\text { nanoparticles }\end{array}$ & $\begin{array}{l}120 \\
\text { s }\end{array}$ & 210 & - & - & 100 \\
\hline Methane & Mo-ZSM5 & 200 & 700 & 110 & 2,450 & $>40$ \\
\hline
\end{tabular}

under microwave heating in relative to the uniform temperature under homogeneous heating. The gas-solid temperature gradient can increase the selectivity of $\mathrm{C}_{2}$ and benzene and reduce the coke formation. They overcome the difficulties in microwaveassisted heterogeneous catalytic processes affected by coking and evaluated the scale of this process. It was found that a 6fold increase in power can handle more than 150-fold reaction streams (Julian et al., 2019a). Table 1 presents the summary of the experimental content of the microwave local thermal effects in this chapter.

\section{THE MICROWAVE PLASMA}

Microwave-induced plasmas (MIPs) technique has attracted wide attention in recent years (Moreno et al., 2019). The schematic diagram of microwave plasma generation is shown in Scheme 2. This technology has no requirement on the dielectric properties of solid phase, because the essence is partially ionized gas and energy storage (Douthwaite, 2007).

Microwave break down metal-dielectric powder mixture (Ti: $\mathrm{CuO}$, etc.) and produce plasma (Batanov et al., 2018). The result showed that the ratio of metal and dielectric powder is important for discharge and chemical reaction. Pulsed microwaves can only sustain plasma with $1.3 \mathrm{~ms}$ in maximum. Then a solid-phase chemical reaction can initiate and be self-sustained by the plasma with high gas temperature. This process takes less time and initiate solid-phase reaction without solvent, while the microwave plasma-chemical technique can also be carried out in solvent. The antenna was heated by microwave $(2.45 \mathrm{GHz}, 500 \mathrm{~W})$ to make the hydrocarbon vaporize and discharge. The gas bubbles with discharge will contact the suspending carbon powders which are good at absorbing microwave energy. Then the discharge phenomenon is disappeared. Through the analysis of composition and structure of solid and liquid phase, it is found that new nano-sized carbonaceous particles and polycyclic aromatic hydrocarbons are produced. The experiment results showed the microwave plasma can accelerate solid-phase reaction and synthesize high-quality products (Lebedev et al., 2014). 


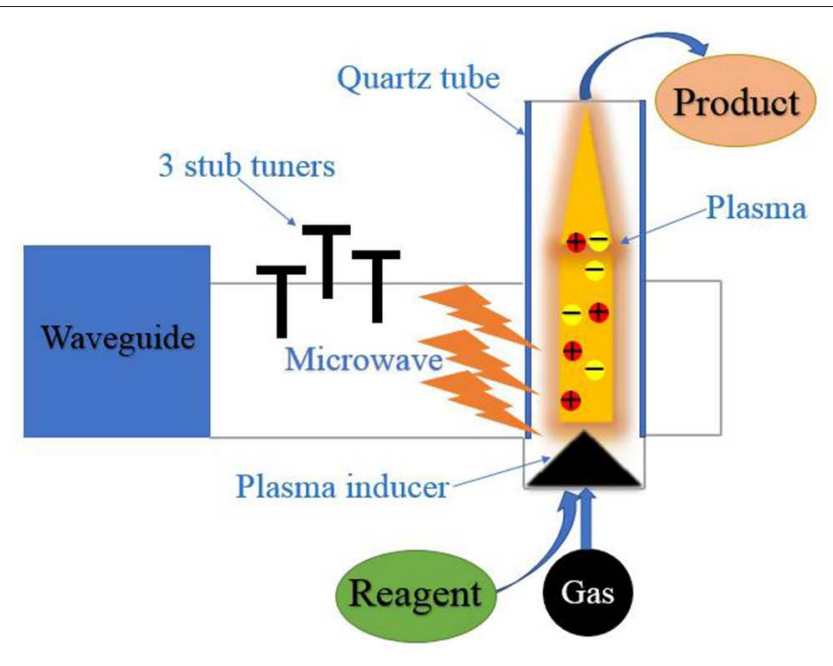

SCHEME 2 | The schematic diagram of the microwave-induced plasma catalysis.

In additional, carbothermal method was used to synthesize molybdenum carbides $\left(\mathrm{Mo}_{2} \mathrm{C}\right)$. But the complex molybdenum salt precursor and excessive carbon will affect the quality of products. MPCVD (microwave-plasma chemical vapor deposition) process can overcome these drawbacks. Zhao et al. (2018) synthesized $\mathrm{Mo}_{2} \mathrm{C}$ by means of microwave plasma treated with methane and hydrogen mixed gases. The hydrogen plasma was excited by $920-\mathrm{W}$ microwave irradiation with frequencies of $2.45 \mathrm{GHz}$ between the two substrate holders. It will form an ellipsoidal plasma ball and can be controlled to heat the Mo foil on the substrates. The carbon atoms and molybdenum atoms in the vapor can generate $\mathrm{Mo}_{2} \mathrm{C}$ on the surface of Mo foil. The high temperature of reaction conditions can be provided by plasma self-heating. Under the condition of high temperature, the ionization of gases of plasma and the energy released by recombining free electrons and positive ions, which can meet the need of plasma glow discharge and stable temperature field. Meantime, the hydrogen plasma can etch the extra carbon on the surface of obtained samples to achieve pure products.

The application of microwave plasma in gas-phase is in the conversion of methane. The output power in the experiment is $300 \mathrm{~W}$ with a frequency of $2.45 \mathrm{GHz}$. $\mathrm{Pt} / \mathrm{Al}_{2} \mathrm{O}_{3}$ is used as plasma catalyst to catalyze methane conversion (Nagazon and Yamaguchi, 2006). The result showed that the yields of ethylene and ethane have an increase on the condition of microwave irradiation. $\mathrm{Pd}-\mathrm{NiO} / \mathrm{\gamma}-\mathrm{Al}_{2} \mathrm{O}_{3}$ and $\mathrm{Pt}-\mathrm{Sn} / \mathrm{\gamma}-\mathrm{Al}_{2} \mathrm{O}_{3}$ are selected as plasma catalysts for the conversion reaction of natural gas to $\mathrm{C}_{2}$ products operating at a frequency of $2.45 \mathrm{GHz}$ and a power of $1.2 \mathrm{~kW}$ (Cho et al., 2010). The mechanism of conversion is free radicals which are produced by electron-methane collisions. The addition of plasma catalyst can lead to an increase of the yield of $\mathrm{C}_{2}$ products from 47 to $63.7 \%$. The hydrogasification of carbon at the presence of microwave plasma was further studied by Kim et al. (2007). They compared plasma reactions with $\mathrm{Ar} / \mathrm{H}_{2}$ mixtures under different injection conditions. One is gas stream
TABLE 2 | Summary of the microwave plasma.

\begin{tabular}{lcccc}
\hline Feed stock & Time & Temp & MW (power) & MW (frequency) \\
\hline Ti: CuO & $1.3 \mathrm{~ms}$ & $1727-2727^{\circ} \mathrm{C}$ & $40-50 \mathrm{~kW}$ & $2.45 \mathrm{GHz}$ \\
n-heptane & $2 \mathrm{~min}$ & $1427^{\circ} \mathrm{C}$ & $500 \mathrm{~W}$ & $2.45 \mathrm{GHz}$ \\
$\begin{array}{l}\text { Mo and } \\
\text { carbon }\end{array}$ & - & - & $920 \mathrm{~W}$ & $2.45 \mathrm{GHz}$ \\
Methane & - & $27-327^{\circ} \mathrm{C}$ & $300 \mathrm{~W}$ & $2.45 \mathrm{GHz}$ \\
$\begin{array}{l}\text { Natural gas } \\
\text { Hydrogasification } \\
\text { of carbon }\end{array}$ & $1 \mathrm{~min}$ & $400-650^{\circ} \mathrm{C}$ & $1,200 \mathrm{~W}$ & $2.45 \mathrm{GHz}$ \\
$\mathrm{CO}_{2}$ & - & 515 and $600 \mathrm{~W}$ & $2.45 \mathrm{GHz}$ \\
\hline
\end{tabular}

contacts with carbon outside the plasma area (post-plasma process), and another is the reaction of carbon particles and gas mixtures occur in the plasma area (plasma process). The plasma process was used a forward microwave power of $600 \mathrm{~W}$ and the post-plasma process was under power of $515 \mathrm{~W}$ at a fixed output frequency of $2.45 \mathrm{GHz}$. The experimental results showed that the production of plasma process is methane, acetylene and ethylene relative to the only product of methane from post-plasma process. The mechanism they concluded is the action of plasma energy and carbon particles can generate more $\mathrm{C}_{2}$ rather than $\mathrm{H}$. Therefore, the most advantageous way for pure $\mathrm{CH}_{4}$ production is the post-plasma process. Chen et al. (2017) overviewed the $\mathrm{CO}_{2}$ conversion in a microwave discharge $(915 \mathrm{MHz})$ for concluding the role of plasma catalysis. The combination of the microwave plasma and Ar plasma-treated $\mathrm{NiO} / \mathrm{TiO}_{2}$ catalyst can significantly enhance the conversion and energy efficiency. The Ar plasma-treated $\mathrm{NiO} / \mathrm{TiO}_{2}$ catalyst could result in a higher concentration of oxygen vacancies. And microwave plasma will facilitate the stepwise vibrational excitation of the $\mathrm{CO}_{2}$ molecule. The synergy leads to the improvement of reaction efficiencies. Table 2 presents the summary of the experimental content of the microwave plasma in this chapter.

\section{ENHANCED ACTIVITY SITE OF CATALYST}

The interfacial activity site of catalysts is a very important factor for the heterogeneous catalytic reaction. The activity site of strong acid ion-exchange resin could be enhanced by the microwave for the reaction from fructose into 5-HMF in acetonewater mixtures (Qi et al., 2008). A comparison was made between microwave and conventional heating, which illustrated that microwave field has a positive effect on the yield and selectivity of the product. The result showed that the yield of 5-HMF is more than $73.4 \%$ and the conversion of fructose is about $94 \%$ under microwave irradiation. They considered that the special effect of microwave and solid catalysts lead to this consequence. The strong acid ion-exchange resin consists of polar sulfo-group. The polar reaction mechanism is that the polar species of reactants will rotate fast in the microwave field and then molecules go from the ground state to the transition state more easily, which results in an increase of reactivity. Guo et al. (2012) compared six solid acid catalysts synthesized by carbonization and sulfonation for 
the conversion of fructose and glucose into 5-HMF. The ligninderived solid acid catalyst showed the best catalytic performance under microwave irradiation owing to its high $-\mathrm{SO}_{3} \mathrm{H}$ group density and carbonization degree. The reaction is irradiated under microwave field of $100 \mathrm{~W}$ with temperature controlled at $100-160^{\circ} \mathrm{C}$. In the presence of microwave field, the dipole-dipole type interaction between the dipolar solvent and polar reactants can produce electrostatic polar effects. In addition, microwave irradiation can strengthen electron transfer of sulphonic groups (Ji et al., 2018). As a result, the heat production and catalytic properties can be synergeticly enhanced.

In addition, there are still some unclear mechanisms in the reactions. CFA (coal fly ash) contains various metal oxides such as $\mathrm{Fe}, \mathrm{Cu}, \mathrm{Mn}$, etc. which makes it can be Fenton-like catalyst and MW absorber. It can catalyze Fenton-like process to decolorize Rhodamine B (RhB) wastewater under the irradiation of microwave (Wang et al., 2019). The reason of decolorization is radicals and $\cdot \mathrm{OH}$ is more important than $\mathrm{HO}_{2}$. and $\mathrm{O}_{2}{ }^{-}$. CFA catalyzed Fenton-like process in the microwave field can achieve a higher degradation rate in a short time relative to other processes. The optimal MW power is $0.1 \mathrm{~kW}$ and the decolorization rate of $\mathrm{RhB}$ is more than $91 \%$. The hot spot and possible non-thermal effect generated by microwave irradiation

TABLE 3 | Summary of enhanced activity site of microwave on catalyst.

\begin{tabular}{lcccc}
\hline Feed stock & Time & Temp & MW (power) & Yield \\
\hline Fructose & $20 \mathrm{~min}$ & $100-180^{\circ} \mathrm{C}$ & - & 73.4 \\
Fructose and glucose & $10 \mathrm{~min}$ & $100-160^{\circ} \mathrm{C}$ & $100 \mathrm{~W}$ & 84 \\
CFA & $20 \mathrm{~min}$ & $53^{\circ} \mathrm{C}$ & $100 \mathrm{~W}$ & 91.6
\end{tabular}

may be the interpretation of the increase of $\mathrm{OH}$. The exact mechanism of this reaction is remains to be verified. Table 3 presents the summary of the experimental content in this chapter. The mechanism of the effect of microwave on the catalyst activity is presumed as shown in the Scheme 3.

\section{THE MICROWAVE ENZYME CATALYSIS}

Enzyme is a substance with high catalytic efficiency. The conditions of the enzymatic reaction are usually mild and can be carried out at low temperatures. The complex spatial structure of enzyme will affect its catalytic activity. At present, most of the explanations for microwave enzymatic reactions are from the perspective of structural changes. Microwave irradiation doesn't damage the nature of the enzyme and destroy the active site. Microwave will change the secondary structure and increase the flexibility of enzyme, which leads to a higher reaction rate. Mazinani et al. (2015) applied microwave-assisted method for trypsin-catalyzed hydrolysis. To verify the effect of microwave on enzyme, they chose azocasein, casein, and BAPNA $[\mathrm{Na}( \pm)$-benzoyl-D/L-arginine-4-nitroanilide hydrochloride] for the digestion experiments by trypsin. This microwave reactor operates at a frequency of $2.45 \mathrm{GHz}$. The hydrolysis results were the same that microwave irradiation can increase the rate of reaction while the bulk temperature was kept at $25^{\circ} \mathrm{C}$. The authors raised the possibility that the secondary structure of trypsin changes when exposed to microwave. Zhang et al. (2012) researched the hydrolysis process of starch by glucoamylase with $800 \mathrm{~W}$ microwave power at $2,450 \mathrm{MHz}$ microwave radiation. By contrasting the SDS-PAGE (Sodium dodecyl sulfate-polyacrylamide gel electrophoresis) of microwave

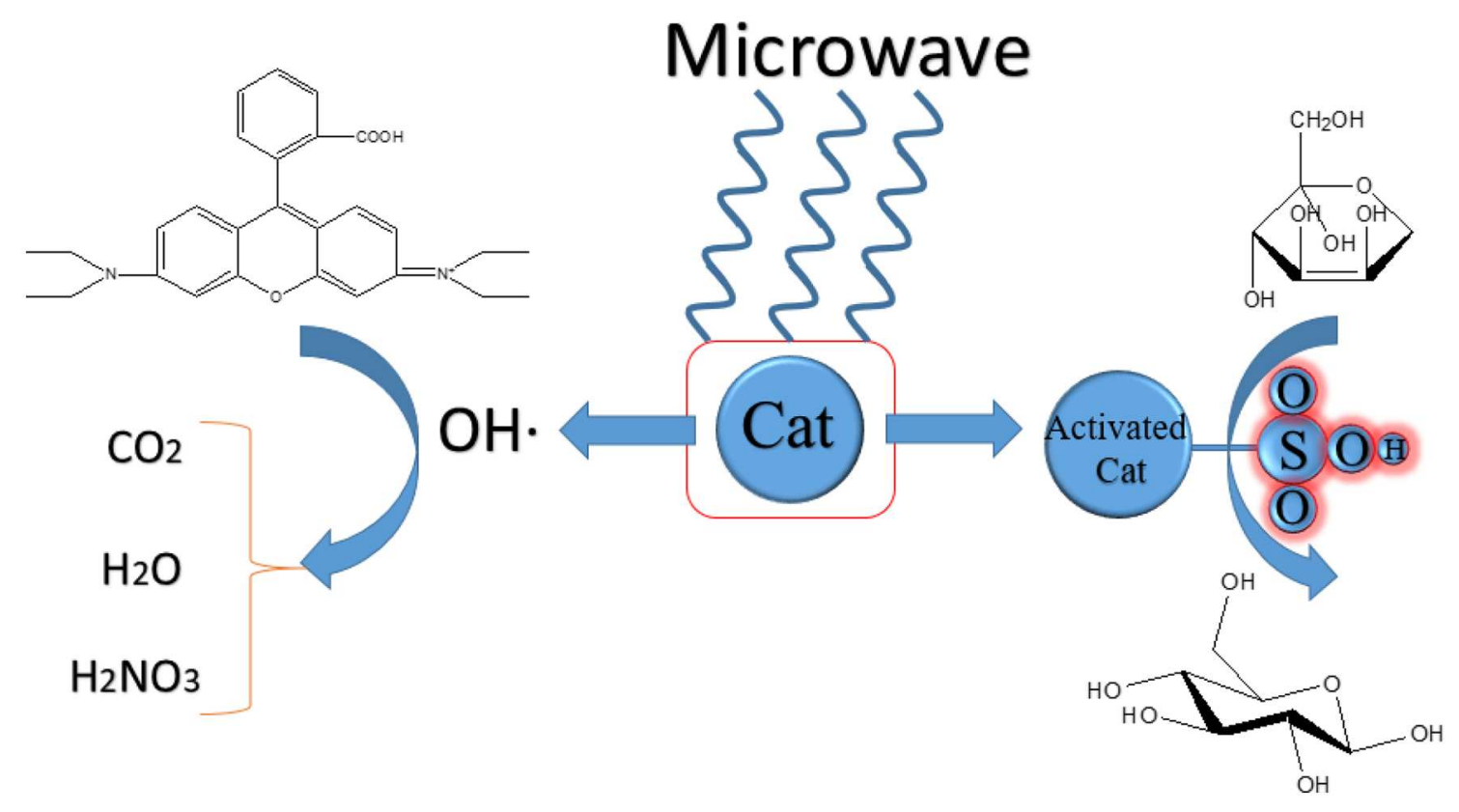

SCHEME 3 | The schematic diagram of microwave on the catalyst activity. 
irradiation and water bath, the molecular weight of glucoamylase is the same which states peptide bonds of glucoamylase is not broken and microwave does not damage the primary structure of glucoamylase. But the circular dichroism (CD) spectra showed the peak height and peak position of microwavetreated samples have varying degrees of change compared to those of the untreated. Therefore, microwave irradiation can affect the hydrogen bonding and increase flexibility of glucoamylase, which may be the explanation of microwave promoting starch hydrolysis.

For the effect of microwave on enzyme, some scholars also gave their interpretations. Wang et al. (2018) catalyzed the synthesis of IOP (isooctyl palmitate) by immobilized lipase QLM under microwave irradiation. The microwave temperature and power were $70^{\circ} \mathrm{C}$ and $640 \mathrm{~W}$, respectively. It showed that enzyme activity of immobilized QLM by microwave-assisted enzymatic reaction is about 9.6 times than that of free lipase QLM in conventional heating. Under optimum conditions of microwave irradiation, the yield of reaction is about $99 \%$ and the reaction time is only $3 \mathrm{~h}$. The reason they speculated is that the polar domains of enzyme can change its flexibility after absorbing microwave energy in the microwave field, which dramatically increase the enzyme activity. Khambhala et al. (2018) treated inoculum for $2,4,6 \mathrm{~min}$ by microwave $(90 \mathrm{~W} ; 2,450 \mathrm{MHz})$ and compared with untreated sample. Microwave irradiation can change cellulase activity without genetically stability. The results showed that microwave-induced cellulase will lead the reversible nature of mutation owing to the non-thermal effect

TABLE 4 | Summary of microwave enzyme catalysis.

\begin{tabular}{|c|c|c|c|c|c|c|}
\hline Feed stock & enzyme & $\begin{array}{c}\text { Time/ } \\
\text { min }\end{array}$ & Temp $/{ }^{\circ} \mathbf{C}$ & MW/W & $\begin{array}{l}\text { MW/ } \\
\text { MHz }\end{array}$ & Yield/\% \\
\hline Casein & Trypsin & 5 & 25 & 20 & 2,450 & 80 \\
\hline Starch & Glucoamylase & 60 & 62 & 800 & 2,450 & - \\
\hline $\begin{array}{l}\text { Palmitic acid, } \\
\text { 2-ethyl hexanol }\end{array}$ & $\begin{array}{l}\text { Thermophilic } \\
\text { lipase QLM }\end{array}$ & 240 & 70 & 640 & - & 99 \\
\hline $\begin{array}{l}\text { Brevibacillus } \\
\text { parabrevis }\end{array}$ & Cellulase & $30-60$ & $50-121$ & 90 & 2,450 & 87.5 \\
\hline
\end{tabular}

and micro-thermal effect. Díaz Ortiz et al. (2018) summarized the non-thermal effect of microwave in photochemical reaction is that microwave can accelerate photoinduction electron transfer. The computational calculations showed that the polarizability of transition states and the stabilization of radicals and triplet states can be influenced through non-thermal effects. Microthermal effect, proposed by Shamis et al. (2012), is different from the thermal effect of bulk temperature changes. They found that the activity of both $\mathrm{LDH}$ (lactate dehydrogenase) and COX (cytochrome coxidase) increases under microwave radiation while the bulk temperature is constant. Table 4 presents the summary of the experimental content of the microwave enzyme catalysis in this chapter. The mechanism of the effect of microwave on the enzyme catalysis is presumed as shown in Scheme 4.

\section{CONCLUDING REMARKS}

It is well-known that microwave irradiation can produce several special effects for reaction intensification owing to dielectric heating. However, the effect of microwave on substances for enhanced reaction is still under discussion. In this context, there are some different mechanisms of microwave and heterogeneous catalysts. The interaction between microwave and solid catalysts can produce local thermal effect as well as special effect. Microwave-induced plasmas (MIPs) technique is considered as an effective way to promote the solid/gas phase reaction. Enzymatic reactions under microwave irradiation can usually be attributed to the change of structure of enzyme. The results of these experiment show that microwave can effectively promote the reaction and increase the yield. This review can provide a method of microwave irradiation to facilitate the heterogeneous catalytic reactions. Furthermore, it summarizes the current mechanism of microwave with different forms of substances, which can give some explanatory ideas for the following scholars.

However, current microwave-assisted catalytic reactions stay on a lab-scale instead of large-scale production. There are some limitations for the industrial applications of microwave field. Gutiérrez-Acebo et al. (2018) researched the effect of

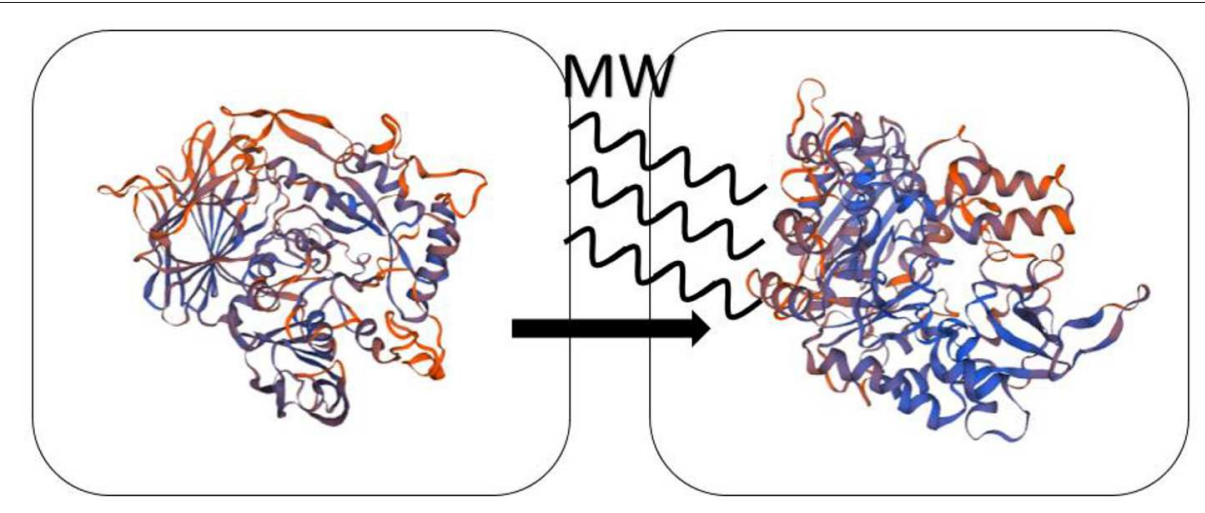

SCHEME 4 | The schematic diagram of the microwave on the enzyme catalysis. 
microwave heating and conventional heating on sulfonic acidfunctionalizing solid catalysts. Then the catalysts are used for the acetalization of glycerol with furfural. It is surprising observed that catalysts prepared with microwaves led to higher conversion but slight lower selectivity compared with the catalyst prepared by conventional heating. The results illustrated that the microwave will affect the properties of catalysts during sulfonation. According to the mechanism of reaction transformation, it is inferred that microwave will reduce Brønsted acid and Lewis acid sites. This reveals that microwaves are not beneficial in all respects. Stankiewicz et al. (2018) discussed the possibility of applying microwave in industry. Large-scale production needs increase dimensions and volume of reaction equipment. Owing to the extensive scale-up, the frequency of microwave must shift from $2.45 \mathrm{GHz}$ to $915 \mathrm{MHz}$. The shift of frequency requires massive studies about physical transport, frequency-related microwave-catalyst interaction, and reaction performance. In addition, the microwave penetration depth and energy distribution are also to be solved. Priecel and LopezSanchez (2018) also doubt the reality for scaling up of microwave assisted reactions. Microwave system can't simply incorporate into the current engineering owing to the significant investment, which is a big limiting factor. It is beneficial to shift the frequency to $915 \mathrm{MHz}$ because extensive reactor construction needs satisfy

\section{REFERENCES}

Adámek, F., and Hájek, M. (1992). Microwave-assisted catalytic addition of halo-compounds to alkenes. Tenahedron Lett. 15, 2039-2042. doi: 10.1016/0040-4039(92)88135-R

Batanov, G. M., Berezhetskaya, N. K., Kossyœ, I. A., and Magunov, A. N. (2018). Initiation of solid-phase chemical reactions in powder mixtures by microwave discharges. Plasma Phys. Rep. 32, 571-576. doi: 10.1134/S1063780X06060109

Binner, E. R., Robinson, J. P., Kingman, S. W., Lester, E. H., Azzopardi, B. J., and Dimitrakis, G., et al. (2013). Separation of oil/water emulsions in continuous flow using microwave heating. Energ. Fuel 27, 3173-3178. doi: 10.1021/ef400634n

Bogdal, D., Lukasiewicz, M., Pielichowski, J., Miciak, A., and Bednarz, S. (2002). Microwave-assisted oxidation of alcohols using magtrievee. Tetrahedron 5, 649-653. doi: 10.1016/S0040-4020(02)01533-8

Chandrasekaran, S., Ramanathan, S., and Basak, T. (2012). Microwave material processing-a review. AIChE J. 58, 330-363. doi: 10.1002/aic.12766

Chen, G., Britun, N., Godfroid, T., Georgieva, V., Snyders, R., and Delplancke-Ogletree, M.-P. (2017). An overview of $\mathrm{CO}_{2}$ conversion in a microwave discharge: the role of plasma-catalysis. J. Phys. D Appl. Phys. 50:084001. doi: 10.1088/1361-6463/aa5616

Cho, W., Kim, Y. C., and Kim, S.-S. (2010). Conversion of natural gas to C2 product, hydrogen and carbon black using a catalytic plasma reaction. J. Ind. Eng. Chem. 16, 20-26. doi: 10.1016/j.jiec.2010.01.027

Díaz Ortiz, Á., Prieto, P., and de la Hoz, A. (2018). A critical overview on the effect of microwave irradiation in organic synthesis. Chem. Rec. 19, 85-97. doi: 10.1002/tcr.201800059

Douthwaite, R. E. (2007). Microwave-induced plasma-promoted materials synthesis. Dalton Trans. 12, 1002-1005. doi: 10.1039/b616787j

Gao, X., Liu, X., Li, X., Zhang, J., Yang, Y., and Li, H. (2018). Continuous microwave-assisted reactive distillation column: pilot-scale experiments and model validation. Chem. Eng. Sci. 186, 251-264. doi: 10.1016/j.ces.2018. 05.036

Gao, X., Shu, D., Li, X., and Li, H. (2019). Improved film evaporator for mechanistic understanding of microwave-induced separation process. Front. Chem. Sci. Eng. 13, 759-771. doi: 10.1007/s11705-019-1816-1 penetration depth. Even the type and arrangement of reactors are required to change accordingly. Moreover, reaction time, energy efficiency and temperature measurement are also issues that are expected to be solved.

Therefore, there is no exact data to prove the existing conjecture and some interpretations are still controversial. In the future, we expect that more applications of microwave in other fields and more scholars can discuss the mechanism of microwave to better meet the needs of heterogeneous catalytic reactions. The large-scale industrial applications of microwaves also require more basic research support.

\section{AUTHOR CONTRIBUTIONS}

HL and XG designed the review idea. CZ, CP, and XG collected literature. $\mathrm{CZ}$ and $\mathrm{XG}$ wrote the paper. $\mathrm{XG}$ and $\mathrm{XL}$ revised this paper.

\section{FUNDING}

The authors acknowledge financial support from the National Nature Science Foundation of China (No. 21878219), and National Key R\&D Program of China (2018YFB0604900).
Guo, F., Fang, Z., and Zhou, T.-J. (2012). Conversion of fructose and glucose into 5-hydroxymethylfurfural with lignin-derived carbonaceous catalyst under microwave irradiation in dimethyl sulfoxide-ionic liquid mixtures. Bioresource Technol. 112, 313-318. doi: 10.1016/j.biortech.2012.02.108

Gutiérrez-Acebo, E., Guerrero-Ruiz, F., Centenero, M., Martínez, J. S., Salagre, P., and Cesteros, Y. (2018). Effect of using microwaves for catalysts preparation on the catalytic acetalization of glycerol with furfural to obtain fuel additives. Open Chem. 16, 386-392. doi: 10.1515/chem-2018-0047

Haneishi, N., Tsubaki, S., Abe, E., Maitani, M. M., Suzuki, E., and Fujii, S. (2019). Enhancement of fixed-bed flow reactions under microwave irradiation by local heating at the vicinal contact points of catalyst particles. Sci. Rep. 9:222. doi: 10.1038/s41598-018-35988-y

Hirota, E., Kawasima, Y., and Ajiki, K. (2017). Internal rotation in trifluoromethylsulfur pentafluoride: $\mathrm{CF}_{3} \mathrm{SF}_{5}$ by fourier transform microwave spectroscopy. J. Mol. Spectrosc. 342, 100-108. doi: 10.1016/j.jms.2017.06.015

Ji, T., Li, Z., Liu, C., and Zhu, J. (2018). Niobium-doped tedplified microway droxymethylfurfural production. Appl. Catal. B Environ. 18, 1-30. doi: 10.1016/j.apcatb.2018.11.013

Jiang, S., Daly, H., Xiang, H., Yan, Y., Zhang, H., Hardacre, C., et al. (2018). Microwave-assisted catalyst-free hydrolysis of fibrous cellulose for deriving sugars and biochemicals. Front. Chem. Sci. Eng. 14, 1-9. doi: 10.1007/s11705-019-1804-5

Julian, I., Pedersen, C. M., Achkasov, K., Hueso, J. L., Hellstern, H. L., Silva, H., et al. (2019a). Overcoming stability problems in microwave-assisted heterogeneous catalytic processes affected by catalyst coking. Catalysts 9, 1-14. doi: 10.3390/catal9100867

Julian, I., Ramirez, H., Hueso, J. L., Mallada, R., and Santamaria, J. (2019b). Non-oxidative methane conversion in microwave-assisted structured reactors. Chem. Eng. J. 377:119764. doi: 10.1016/j.cej.2018.08.150

Khambhala, P., Paliwal, P., and Kothari, V. (2018). Microwave mutagenesis of brevibacillus parabrevis for enhanced cellulase production, and investigation on thermostability of this cellulase. J. Microbiol. Food Sci. 6, 1213-1217.doi: 10.1101/064410

Kim, Y., Abbate, S., Ziock, H., Anderson, G. K., and Rosocha, L. A. (2007). Hydrogasification of carbon in an atmospheric pressure microwave plasma. IEEE T. Plasma Sci. 35, 1677-1681. doi: 10.1109/TPS.2007.910139 
Lebedev, Y. A., Konstantinov, V. S., Yablokov, M. Y., Shchegolikhin, A. N., and Surin, N. M. (2014). Microwave plasma in liquid n-heptane: a study of plasma-chemical reaction products. High Energ. Chem. 48, 385-388. doi: 10.1134/S0018143914060058

Li, H., Cui, J., Liu, J., Li, X., and Gao, X. (2017). Mechanism of the effects of microwave irradiation on the relative volatility of binary mixtures. AIChE J. 63, 1328-1337. doi: 10.1002/aic.15513

Li, H., Liu, J., Li, X., and Gao, H. (2019a). Microwave-induced polar/nonpolar mixture separation performance in a film evaporation process. AIChE J. 65, 745-754. doi: 10.1002/aic.16436

Li, H., Meng, Y., Shu, D., Zhao, Z., Yang, Y., Zhang, J., et al. (2019b). Breaking the equilibrium at the interface: Microwave-Assisted Reactive Distillation (MARD). React. Chem. Eng. 4, 688-694. doi: 10.1039/C8RE00254A

Li, H., Zhao, Z., Xiouras, C., Stefanidis, G. D., Li, X., and Gao, X. (2019c). Fundamentals and applications of microwave heating to chemicals separation processes. Renew. Sust. Energ. Rev. 114:109316. doi: 10.1016/j.rser.2019.109316

Mazinani, S. A., DeLong, B., and Yan, H. (2015). Microwave radiation accelerates trypsin-catalyzed peptide hydrolysis at constant bulk temperature. Tetrahedron Lett. 56, 5804-5807. doi: 10.1016/j.tetlet.2015.09.003

Mishra, S., Sahu, T. K., Verma, P., Kumar, P., and Samanta, S. K. (2019). Microwave-assisted catalytic degradation of brilliant green by spinel zinc ferrite sheets. Acs Omega. 4, 10411-10418. doi: 10.1021/acsomega. 9 b00914

Moreno, S. H., Stankiewicz, A. I., and Stefanidis, G. D. (2019). A twostep modelling approach for plasma reactors - experimental validation for $\mathrm{CO}_{2}$ dissociation in surface wave microwave plasma. React. Chem. Eng. 4, 1253-1269. doi: 10.1039/c9re00022d

Nagazon, H., and Yamaguchi, M. K. T. (2006). Characteristics of methane conversion under combined reactions of solid catalyst with microwave plasma. J. Chem. Eng. Jpn. 3, 314-320. doi: 10.1252/jcej.39.314

Nayak, S. N., Bhasin, C. P., and Nayak, M. G. (2019). A review on microwaveassisted transesterification processes using various catalytic and noncatalytic systems. Renew. Energ. 143, 1366-1387. doi: 10.1016/j.renene.2019. 05.056

Oh, Y., Armstrong, D. L., Finnerty, C., Zheng, S., Hu, M., Torrents, A., et al. (2017). Understanding the ph-responsive behavior of graphene oxide membrane in removing ions and organic micropollulants. J. Membrane Sci. 541, 235-243. doi: 10.1016/j.memsci.2017.07.005

Prakash, P., Kamble, L., and Sheeba, K. N. (2015). Experimental studies on biomass pyrolysis using microwave radiation. Energ. Source Part A 37, 2675-2683. doi: 10.1080/15567036.2012.713079

Priecel, P., and Lopez-Sanchez, J. A. (2018). Advantages and limitations of microwave reactors: from chemical synthesis to the catalytic valorization of biobased chemicals. Acs Sustain Chem. Eng. 7, 3-21. doi: 10.1021/acssuschemeng.8b03286

Qi, X., Watanabe, M., Aida, T. M., and Smith, J. R. L. (2008). Catalytic dehydration of fructose into 5-hydroxymethylfurfural by ion-exchange resin in mixed-aqueous system by microwave heating. Green Chem. 10, 799-805. doi: 10.1039/b801641k

Ren, J., Ren, M., Wang, D., Lin, J., and Li, Z. (2015). Mechanism of microwave-induced carbothermic reduction and catalytic performance of $\mathrm{Cu} /$ activated carbon catalysts in the oxidative carbonylation of methanol. J. Therm. Anal. Calorim. 120, 1929-1939. doi: 10.1007/s10973-015-4 $519-\mathrm{y}$
Roy, S., Humoud, M. S., Intrchom, W., and Mitra, S. (2017). Microwave-induced desalination via direct contact membrane distillation. Acs. Sustain. Chem. Eng. 6, 626-632. doi: 10.1021/ acssuschemeng.7b02950

Saidi, A., and Azari, K. (2005). Carbothermic reduction of zinc oxide concentrate by microwave. J. Mater. Sci. Technol. 5, 724-728. doi: 10.1016/j.jallcom.2005.0.4.009

Sajjadi, B., Abdul Aziz, A. R., and Ibrahim, S. (2014). Investigation, modelling and reviewing the effective parameters in microwave-assisted transesterification. Renew. Sust. Energ. Rev. 37, 762-777. doi: 10.1016/j.rser.2014.05.021

Shamis, Y., Taube, A., Croft, R. J., Crawford, R., and Ivanova, E. (2012). Influence of $18 \mathrm{GHz}$ microwave radiation on the enzymatic activity of Escherichia coli lactate dehydrogenase and cytochrome c oxidase. J. Phy. Sci. Appl. 6, 143-151. Available online at: http://ro.uow.edu.au/hbspapers/2948

Stankiewicz, A., Sarabi, F. E., Baubaid, A., Yan, P., and Nigar, H. (2018). Perspectives of microwaves-enhanced heterogeneous catalytic gas-phase processes in flow systems. Chem. Rec. 19, 40-50. doi: 10.1002/tcr.201800070

Vakili, R., Xu, S., Al-Janabi, N., Gorgojo, P., Holmes, S. M., and Fan, X. (2018). Microwave-assisted synthesis of zirconium-based metal organic frameworks (MOFs): optimization and gas adsorption. Microporous Mesoporous Mater. 260, 45-53. doi: 10.1016/j.micromeso.2017.10.028

Wang, L., Zhang, Y., Zhang, Y., Zheng, L., Huang, H., and Wang, Z. (2018). Synthesis of 2-ethylhexyl palmitate catalyzed by enzyme under microwave. Appl. Biochem. Biotech. 185, 347-356. doi: 10.1007/s12010-017-2666-2

Wang, N., Hu, Q., Du, X., Xu, H., and Hao, L. (2019). Study on decolorization of Rhodamine B by raw coal fly ash catalyzed fenton-like process under microwave irradiation. Adv. Power Technol. 30, 2369-2378. doi: 10.1016/j.apt.2019.07.020

Yi, H., Yang, Z., Tang, X., Zhao, S., Gao, F., Wang, J., et al. (2018). Promotion of low temperature oxidation of toluene vapor derived from the combination of microwave radiation and nano-size $\mathrm{Co}_{3} \mathrm{O}_{4}$. Chem. Eng. J. 333, 554-563. doi: 10.1016/j.cej.2017.09.178

Yuan, H., Yang, B. L., and Zhu, G. L. (2009). Synthesis of biodiesel using microwave absorption catalysts. Energ. Fuel. 23, 548-552. doi: 10.1021/ef800577j

Zhang, M., Wang, M., Xu, B., and Ma, D. (2019). How to measure the reaction performance of heterogeneous catalytic reactions reliably. Joule 3, 2876-2883. doi: 10.1016/j.joule.2019.11.005

Zhang, X., Cao, T., Tian, X., and Gai, D. (2012). Effect of microwave irradiation on the structure of glucoamylase. Process Biochem. 47, 2323-2328. doi: 10.1016/j.procbio.2012.09.010

Zhao, H., Cai, K., and Ma, Z. (2018). Synthesis of molybdenum carbide superconducting compounds by microwave- plasma chemical vapor deposition. J. Appl. Phys. 123:053301. doi: 10.1063/1.5010101

Conflict of Interest: The authors declare that the research was conducted in the absence of any commercial or financial relationships that could be construed as a potential conflict of interest.

Copyright (c) $2020 \mathrm{Li}$, Zhang, Pang, Li and Gao. This is an open-access article distributed under the terms of the Creative Commons Attribution License (CC BY). The use, distribution or reproduction in other forums is permitted, provided the original author(s) and the copyright owner(s) are credited and that the original publication in this journal is cited, in accordance with accepted academic practice. No use, distribution or reproduction is permitted which does not comply with these terms. 